group of properties in both sections, an introduction outlines the theory, experimental procedures, and selected references.

The index must be used with care to find the specific property of a specific material. In checking for the specific material directly, I found references to figures or tabulations dealing only with that material. Much additional information exists in the collective tables, but can be found only by looking up the particular property. The publisher does not make the task any easier, since the running head at the top of the page identifies only Section 1 or Section 2. The table of contents is quite brief and appears in an inconspicuous spot on the back of the last page of the introductory matter.

A brief scan located just a few errors, judged to be minor. In checking on ZnS, I found Table 1.1.1.2 gives the $\beta Z \mathrm{ZnS}$ crystal system as cubic. Subsequent tables usually list merely "ZnS"; in Table 1.1.1.4.5 ZnS also appears in a hexagonal listing. In other places the listing is "ZnS (CVD)"; an examination of the data indicates that this must be the cubic form. Refractive index data on these materials are found in a variety of forms on pages 29,31, 33, 234, 247, and 265. Some of these entries imply that $\mathrm{ZnS}$ is also available as "Irtran 2," for which "Infrared transmission" in the index also leads to additional data on page 242.

Having found some imperfections in this massive work, I can now complete my review by saying that I expect to find this volume very useful in my work and would hate to be without it. Most materials scientists will, I believe, feel the same way. Reviezver: Kurt Nassau is a member of the technical staff at ATET Bell Laboratories, Murray Hill, N].

\section{Strong Metal-Support Interactions}

\section{Edited by R.T.K. Baker, S.J. Tauster,} and J.A. Dumesic

(American Chemical Society, 1986)

This volume in the ACS Symposium Series presents the papers from a symposium held at the 189th Meeting of the American Chemical Society in Miami Beach, Florida, April 28 through May 3, 1985. It includes 21 papers discussing metal-support interactions, a topic of continuing interest among catalytic chemists but now of importance to those involved in understanding other materials, such as metal-metal oxide interfaces in electronics. This symposium focuses on those aspects strongly coupled to heterogeneous catalysis.

The topics range from a review, through detailed microscopic and kinetic characterizations of high-surface-area catalysts, to important studies of model systems. This book brings together the thinking of experts from around the world who are working in this area.
Because of the detailed nature of these papers which, for the most part, represent new and ongoing research, the book will be most valuable to experts in the field. However, Tauster's overview is particularly noteworthy in its attempt to assess the present status and understanding of this important field. As such, it will be of considerable interest to newcomers to metal-support interactions. While the center of gravity of the reported work lies in the popular metal-titania systems, other areas are given sufficient coverage to provide useful breadth and an indication of the generality of the important metal-support interactions

As a participant in this field, I found the papers to be of uniformly high quality and to contain interesting observations and speculations which stimulated anew my thinking on this subject.

Reviewer: J.M. White is the Norman Hackerman Professor of Chemistry at the University of Texas at Austin.

\section{Electron Energy Loss Spectroscopy in the Electron Microscope}

\section{R.F. Egerton}

\section{(Plenum Press, 1986)}

Electron energy loss spectroscopy (EELS), as a technique for elemental analysis, dates from the pioneering work of Hillier and Baker at RCA in 1944. For much of the succeeding 40 years, EELS remained a laboratory curiosity, overshadowed by the successes of fluorescent $x$-ray microanalytical techniques. In the past ten years, however, with the development of electron microscopes combining small diameter probes, high beam energies, and good vacuum engineering, EELS has become an analytical tool of considerable importance. This new book, by one of the workers who has done most to establish the technique, finally marks the transition of transmission electron microscopy from a promising newcomer to an established performer.

The book is divided into five major sections, starting with an introduction and general survey of electron spectroscopy. Next comes a study of EELS instrumentation. This chapter is particularly welcome as it is perhaps the first detailed exposition of many of these topics in a readily accessible form. Anyone attempting to set up an EELS system for the first time will be grateful to have this material.

The next section, a detailed and thorough review of electron scattering theory, provides a comprehensive overview of all aspects of both elastic and inelastic scattering phenomena. While some of the theoretical material is quite advanced, the author has been careful to start each chapter with a review of basic concepts, and then build toward more complex ideas.
The last two chapters consider the application of EELS to qualitative and quantitative elemental analysis, and other applications of EELS including structural determinations using Extended Fine Structure (EXELFS), Near Edge Structure (XANE), and Compton Scattering methods.

The overall presentation of the book is good, although the reproduction of some of the experimental spectra, apparently photographed from screen displays, is less than ideal. Considerable care seems to have been taken to ensure uniform notation throughout the text and this, together with the careful explanations, excellent drawings, and practical illustrations, will make the book ideal for teaching use at the graduate level. The volume is further enhanced for use as a reference source by some useful appendices, such as a tabulation of characteristic plasmon loss values and a detailed listing of edge energies, a compilation in reasonably generic FORTRAN of the source code for some of the programs discussed in the text, and a good index.

The bibliography deserves a special word, as it is both comprehensive and fully annotated. Many of the references cited here are difficult to find elsewhere and this portion of the book will surely be one of the most heavily used. Anyone who is now using, or who is planning to use, EELS in an electron microscope will find this book invaluable as a reference and as an experimental guide.

Reviewer: David C. Joy is a member of the technical staff at ATET Bell Laboratories, Murray Hill, NJ.

\section{Applied Polymer Science Edited by R.W. Tess and G.W. Poehlein}

\section{(American Chemical Society, 1985)}

Applied Polymer Science covers a wide range of topics in current applications of polymers. The volume is divided into eight segments, each containing several chapters and making a total of 54 . An introduction by Herman Mark provides a historical perspective of the field of polymers. The chapter by C.E. Carraher, Jr. and R.B. Seymour lays the foundation for all subsequent chapters. The second segment reviews in depth various modes of polymerization, including major industrial processes, such as free-radical, ionic, and condensation reactions. Block copolymer and multicomponent systems are also discussed in separate chapters. The next segment deals with structure-property relationships, with specific concentration on transport behavior, fracture mechanics, and flammability. Up to this point, the volume reads more like a graduate-level text, all the subjects

Continued 